\title{
O PAPEL DA MULHER E DO CAIPIRA NA CONSTRUÇÃO DE SENTIDOS E IDENTIDADES URBANAS
}

Débora Freitas

Jornalista, especializada em Mídia, Informação e Cultura pelo Celacc (ECA/USP)

Resumo

A partir do trabalho desenvolvido pela Orquestra Feminina Viola de Saia, este artigo discute a cultura como mediadora da construção de subjetividades, de sentidos e de novas identidades. Em uma seara tipicamente masculina - música caipira e viola - nove mulheres apresentam um trabalho que sofre claras influências de suas raízes familiares. Isso acontece em um ambiente muitas vezes hostil à manutenção das tradições caipiras, o meio urbano. $\mathrm{O}$ trabalho da orquestra só se torna possível a partir do sentimento de igualdade social que este tipo de ação desperta nas integrantes do grupo, que veem na cultura a possibilidade da formação de um espaço de conflitos.

Palavras-chave: viola caipira; violeira; música caipira; cultura

\section{Abstract}

From the work of Orquestra Feminina Viola de Saia, this article discusses the culture as a mediator of the construction of subjectives, meanings and new identities. In a tipically male space - folk music and caipira viola - nine women have a job that suffers clear influences from their family roots. This happens in a environment often hostile to preservation of traditions from country, the urban environment. The work of the orchestra is only possible from the sense of social equality that this type of action awakens the group members, who see culture in the possibility of forming an area of conflicts.

Keywords: caipira viola; violist ; folk music; culture

\section{Resumen}

A partir del trabajo de la Orquestra Feminina Viola de Saia, este artículo analiza la cultura como un mediador de la construción de las subjetividades, significados y nueva identidades. En un entorno tipicamente masculino - la música regional y la viola caipira - nueve mujeres tienen un trabajo que sufre claras influencias de sus raíces familiares. Esto ocurre en un entorno hostil a preservación de las tradiciones del interior, el ambiente urbano. El trabajo de la orchestra, sólo es possible por el sentido de la igualdad social que este tipo de acción despierta en los miembros del grupo, que ven la cultura como posibilidad de formación de una zona de conflicto.

Palabras clave: viola caipira; violista; música regional; cultura 


\section{Introdução}

Este artigo discute a cultura como elemento de construção de sentidos e de novas identidades, a partir do momento em que dois valores não hegemônicos, o feminino e o rural, se apropriam de dois valores hegemônicos, o masculino e o espaço urbano.

O cenário é a cidade de São Paulo, considerada um caldeirão cultural pela diversidade de migrantes e imigrantes que chegam e estabelecem uma relação instrumental com a cidade, ou seja, vêm em busca de oportunidades inexistentes em seus locais de origem. Uma das formas de sobrevivência desses povos é justamente a manutenção de seus hábitos culturais frente aos desdobramentos do neoliberalismo que destrói as identidades culturais (FERREIRA, 1997, p. 23).

Os personagens são as nove mulheres integrantes da Orquestra Feminina Viola de Saia, primeira do gênero criada na capital paulista, que desenvolvem um trabalho cultural considerado subalterno, pelas características de resistência e humanização. Nesse contexto, essas mulheres passam a ter um poder simbólico nas figuras do prestígio e do reconhecimento de uma pequena comunidade.

Dessa forma, a cultura torna-se um espaço de conflitos, tendo como papel fundamental oferecer novas possibilidades para orientar práticas sócio-políticas-culturais inovadoras. (MANZINI-COVRE, 1996, p. 226)

$\mathrm{O}$ artigo pretende mostrar, por meio das atividades da Orquestra Feminina Viola de Saia, uma das inúmeras possibilidades da produção das subjetividades em uma cidade contemporânea e capitalista, bem como o sentimento de pertencimento despertado nessas mulheres, a partir da apropriação de uma tradição culturalmente creditada aos homens, o tocar viola.

\section{Orquestra Feminina Viola de Saia}

A Orquestra Feminina Viola de Saia foi fundada em outubro de 2007, na cidade de São Paulo, pela violeira, cantora e compositora Fabíola Mirella. A primeira orquestra de violas formada exclusivamente por mulheres é composta por nove artistas, com idades que variam entre 10 e 66 anos. Seis das integrantes tocam viola, uma toca acordeom e duas percussão. $\mathrm{O}$ repertório da orquestra é formado exclusivamente por músicas chamadas caipira ou de raiz, principal referência musical de todas as integrantes. Atualmente, o grupo ensaia uma vez por semana, cerca de duas horas, para a gravação de seu primeiro CD. 
Desde a fundação, a orquestra já fez alguns shows pelo Estado de São Paulo, como a abertura do Festival Zé Carreiro, de Porto Ferreira, do I Festival Tião Carreiro, na cidade de Ibiúna e participaram do Revelando São Paulo 2009. O grupo já se apresentou no programa Manhã Sertaneja, da Rede Vida de televisão e no programa Raízes do Brasil, na rádio Cultura AM.

Os ensaios são feitos aos sábados à tarde, pois todas as integrantes da orquestra têm outras atribuições profissionais durante a semana. O espaço utilizado é uma escola de viola e violão, na zona norte de São Paulo, fundada pelo violeiro Sérgio Penna. No local, além das aulas e dos ensaios da Viola de Saia, é possível respirar 24 horas da cultura caipira, que passa pelas modas de viola do interior de São Paulo, que falam do homem do campo, seus anseios e paixões; pelas canções pantaneiras, que descrevem a natureza e a saga de quem escolheu - ou foi escolhido - ser violeiro; e as melodias mineiras, que cantam a religiosidade e a diversões locais. Além dos alunos, o espaço recebe amigos, vizinhos, curiosos e qualquer interessado em conhecer um pouco mais sobre viola caipira.

\section{Componentes da Orquestra}

As nove mulheres da Orquestra Feminina Viola de Saia têm em comum o gosto pela música caipira e pela viola, herdado de seus familiares ou do local onde nasceram. Elas trabalham para manter, na cidade grande, essas manifestações artísticas e transportam o ambiente rural para a dura realidade da cidade de pedras. Segue uma breve apresentação das componentes do grupo, em ordem alfabética.

Alessandra Maria de Oliveira é paulistana, tem 37 anos e toca percussão e cavaquinho na Orquestra. Ela é irmã da violeira Maria Cristina que, juntamente com Fabíola Mirella, a convidou para fazer parte do grupo. Sua história musical começou quando tocava caixa de guerra na fanfarra da escola, aos 10 anos. A música caipira sempre fez parte de sua vida, influência de seus pais. Alessandra já tocou em um grupo de pagode e atualmente é gerente comercial de uma empresa de informática.

Celina Paixão nasceu em São Caetano do Sul, tem 48 anos, toca viola e faz segunda voz. Também é professora de Geografia nas redes municipal e estadual de ensino. Casada com o violeiro Carlos, canta no grupo de música regional e caipira do qual ele faz parte. Há dois anos aprendeu a tocar viola. $\mathrm{O}$ gosto pela música caipira veio das reuniões familiares aos domingos no fundo do quintal da casa de seus pais, onde a mãe e as tias faziam duetos. A influência da música caipira vem da origem da família, São José do Rio Preto, cidade do interior paulista.

Fundadora da Orquestra Feminina Viola de Saia, Fabíola Mirella tem 28 anos e nasceu na cidade de São Paulo. Ela é responsável pela viola solo e primeira voz na 
orquestra. Aos 14 anos iniciou um curso básico de violão popular e aos 18 teve o primeiro contato com a viola caipira, quando passou a fazer parte da Orquestra de Viola Caipira de São José dos Campos, regida na época pelo violeiro Braz da Viola. Fabíola cursou viola por três anos no Centro de Estudos Musicais Tom Jobim - CEM. Desde 2004 ela leciona viola e integra o Grupo Violeiros Matutos, fundado por Sérgio Penna. Atualmente Fabíola estuda técnica em Música no Centro Paula Souza.

Irani Barbosa tem 34 anos e nasceu em Urandi, na Bahia. Na orquestra ela toca viola solo e faz segunda voz. O gosto pela música surgiu aos quatro anos, com o pai que tocava violão e a incentivava a cantar em dupla com a irmã. Mais tarde, Irani conheceu a viola caipira e passou a se dedicar à música de raiz. As atividades musicais são conciliadas com seu trabalho em uma casa de família.

Izabele Caetano de Oliveira tem 11 anos e nasceu na capital paulista. Na orquestra ela é responsável pela viola base. Seu gosto pela música caipira surgiu nas viagens feitas para visitar os familiares do pai na região de Marília. A família ia ouvindo músicas de ícones da música caipira, como Tião Carreiro e Pardinho, entre outros tantos artistas. Por volta dos seis anos Izabele acompanhava o pai nas aulas de viola quando o professor a incentivou a aprender a tocar violão. Mas foram apenas quatro aulas do instrumento, ela gostava mesmo era da viola. Há dois anos Izabele passou a ter aulas de viola com Fabíola Mirella, quando surgiu o convite para participar da orquestra.

Maria Clara de Oliveira é filha de Alessandra e sobrinha de Maria Cristina. Aos 10 anos de idade foi a última integrante a entrar para a Orquestra, onde toca percussão junto com a mãe. Ela também toca violão.

Maria Cristina de Oliveira, irmã de Alessandra, tem 40 anos e também nasceu na cidade de São Paulo. Ela faz primeira voz e viola base na Viola de Saia. A família veio do interior para a capital e o pai, um homem que trabalhava no campo, não perdeu suas raízes e costumes. Ele ouvia músicas caipiras e levava os filhos para passar férias no interior. Maria Cristina também toca violão e há dois anos decidiu aprender a tocar viola, por influência do namorado violeiro, Hamilton. Proprietária de uma empresa de informática, atualmente ela estuda canto popular.

Nancy Gaspar Junqueira é natural de São Paulo, tem 60 anos e toca sanfona na Viola de Saia. Professora de música, também toca na Orquestra Sanfônica de São Paulo. Nancy vive da música e chegou à orquestra por meio de uma amiga, aluna de Fabíola Mirella.

Veneranda Maria de Jesus tem 66 anos e nasceu em uma fazenda na cidade de Nanuque, em Minas Gerais. Na Viola de Saia ela toca viola base. Ela conta que onde 
nasceu não existia rádio. Seu primeiro contato com a música foi aos quatro anos, quando ouviu o pai tocar viola. Todas as tardes ele reunia a família para tocar, cantar e dançar. Depois de adulta, Veneranda foi morar na cidade e perdeu contato com a viola do pai, mas nunca esqueceu o instrumento e a vontade de aprender a tocá-lo, desejo que realizou há cinco meses. Ela também toca acordeom e teclado.

\section{O caipira e a cultura cabocla}

Câmara Cascudo (2002) define o caipira como "homem ou mulher de pouca instrução, que não mora em centros urbanos. Trabalhador rural, de beira-rio ou beira-mar ou de sertão. É também chamado de caboclo, jeca, matuto, roceiro.”

No início do século XX, o escritor Monteiro Lobato criou o personagem Jeca Tatu, o qual chamava de caboclo - mestiço de branco com índio - e tratava como parasita da terra, por tirar o que precisava para sua sobrevivência, sem se importar com a necessidade do dia seguinte. Para Monteiro Lobato, o caboclo também era um ser alheio aos acontecimentos que se davam fora de seu habitat, permanecendo 'acocorado' enquanto o tempo passava e a vida acontecia. Era uma crítica do autor à alienação do povo brasileiro frente às questões sociais e políticas do Brasil naquela época, pelo claro contraste de seus modos com a excitante Europa, que vivia um período de plena modernidade.

No entanto, com as transformações culturais ocorridas no decorrer do século XX o estereótipo do caipira, ou caboclo parasita, criado por Monteiro Lobato deixou de existir e outras características foram reconhecidas e adicionadas à construção da identidade dos indivíduos que não faziam parte do universo urbano.

\footnotetext{
"Não se resume ao caipira histórico, nascido das relações de poder entre o colonizador e o índio. Aliás, o caipira é a síntese dos dois polos, é o mameluco. E também do negro e do italiano, dos colonos vindos com os ventos da virada do século XX. Também não é o caipira inculto, entrave da civilização moderna, que torce o nariz à velocidade futurista das locomotivas e aos modernos meios produtivos. Sua opção aversa à modernidade ocorre de uma atitude inata de recolhimento, não de enfrentamento, pois o caipira, comprovando sua essência para o fronteiriço, paira entre a pré-modernidade e a modernidade." (SOUSA, 2005, p. 35)
}

Para Brandão (1984), o caipira é um construtor de sentidos, pois apresentase como precursor de uma "cultura cuja riqueza múltipla e densa desafia em todos nós mais do que uma curiosidade passageira". Essa cultura seria fruto de sua própria existência, desenvolvida na vida simples e rural, longe das influências capitalistas que permeiam o espaço urbano.

A Semana de Arte Moderna, criada e realizada por um grupo de artistas e intelectuais na cidade de São Paulo, em 1922, trouxe o caipira para rodas e discussões 
da cidade e acabou com o significado pejorativo criado por Lobato.

\begin{abstract}
"Escritores como Oswald de Andrade e Graça Aranha, pintores como Segall, Anita Malfatti, Tarsila do Amaral e Di Cavalcanti, poetas como Mário de Andrade e Manuel Bandeira e o maestro Villa-Lobos tentavam renovar as artes e a forma de pensar do país, valorizando tudo o que era nacional, verdadeiro, nativo, original. A série de caipiras pintada por Almeida Júnior se transformara em forte inspiração do movimento das artes plásticas da época." (NEPOMUCENO, 1999, p. 19).
\end{abstract}

\title{
A viola, o violeiro e a moda caipira
}

Segundo Cascudo (2002, p. 728), a viola é um "instrumento de cordas dedilhadas, cinco ou seis, duplas, metálicas. (...) No estado de São Paulo é comum a viola de cinco cordas duplas, assim denominadas. (...) A viola folclórica brasileira é o instrumento característico da chamada música caipira.”

Trazida para o Brasil no século XVI pelos portugueses, a viola nessa época fez parte de um sem número de manifestações no país e passou a ser um instrumento de grande popularidade. Nesse período a viola não era considerada um instrumento tipicamente caipira, pelo contrário, era utilizada para acompanhar encenações artísticas, como os autos de Gil Vicente, romarias, e também em bailes e cancioneiros. (SOUSA, 2005, p.42).

Entre os séculos XIX e XX, o caipira brasileiro passou a fazer adaptações, com encordoamentos de tripa e de arame e a viola passou a ser um instrumento característico da chamada música caipira. Tocar viola tornou-se uma tradição oralmente passada de pai para filho, criando a figura do violeiro cantador, responsável pela animação das festas populares. (NEPOMUCENO, 1999, p. 72).

A música caipira, ou moda de viola, mostra com frequência a relação do ser humano com o campo e suas tensões em relação à cidade grande. "As críticas à vida urbana estariam sempre presentes nesse tipo de música. Indo para a cidade, o matuto deixava de gozar de seu maior privilégio: o calor da convivência com seus parceiros de mundo.” (NEPOMUCENO, 1999, p. 34).

Em meados do século XX, o violeiro, ou "caboclo cantador que só queria estar no meio do furacão das transformações" volta com seu instrumento para os grandes centros e começa a difundir a música caipira. (NAPOMUCENO, 1999, p. 33).

A primeira música caipira gravada foi a moda Jorginho do Sertão, em 1929, de autoria do jornalista, poeta, folclorista e compositor Cornélio Pires. A partir daí, o mercado fonográfico, de olho em um nicho que se criava, lançou uma série de artistas caipiras, como João Pacífico e as duplas Tonico e Tinoco e Alvarenga e Ranchinho. 
É preciso salientar que a música caipira ou de raiz tratada neste artigo não é a mesma música sertaneja tocada pelas rádios e que fazem parte de uma cultura hegemônica que está nos grandes meios de comunicação. A atual música sertaneja com certeza nasceu sob a influência da música caipira, mas a tecnologia, os instrumentos elétricos e a vontade de falar de amor, criaram um novo formato, considerado atualmente um fenômeno cultural.

\section{Cultura marginalizada}

A viola e a música caipira tornaram-se um instrumento de resistência cultural, que apesar dos modernismos e tecnologias do mundo capitalista continuam a fazer parte da vida dos caipiras de nascimento e dos que se encantam pela cultura sertaneja.

Porém, a atenção da mídia voltada para os músicos sertanejos românticos, em detrimento da música verdadeiramente sertaneja, que fala do campo e do caipira, tornou a segunda marginalizada. Nesse caso, baseado nas teorias de Antonio Gramsci, o termo cultura subalterna ou cultura de classes subalternas se encaixa perfeitamente nesse segmento. A viola e a música caipira têm pouca aceitação nos espaços urbanos e nas grandes mídias.

O conceito de cultura, segundo Thompson (2000, p. 165), está ligado ao estudo das formas simbólicas, sendo na concepção clássica um processo de desenvolvimento intelectual ou espiritual.

\section{Identidade e feminino}

A Orquestra Feminina Viola de Saia, que reúne mulheres de diferentes idades e classes sociais, luta pela manutenção de uma identidade cultural, parte integrante das lutas de classe pela igualdade social.

Segundo Hall (1997, p. 8), a identidade na concepção sociológica faz a ponte entre o "interior" e o "exterior", entre os mundos público e privado, o que tornaria o sujeito fragmentado, composto de muitas identidades.

"Isso produz o sujeito pós-moderno, conceituado como isento de identidade fixa, permanente ou essencial. A identidade tornou-se uma "festa móvel": formada e transformada continuamente em relação às maneiras pelas quais somos representados ou tratados nos sistemas culturais que nos circundam. Ela é histórica, não biologicamente definida." (HALL, 1997, p. 9, 10).

A nova identidade vai além das lutas pela igualdade social, pode ser suportada pela cultura do feminino, voltada à construção interna e baseada no ser, que se sobrepõe à cultura do masculino, que constrói externamente e se baseia no ter (COVRE, 
1996, p. 24).

Ao se aventurar em um território quase que exclusivamente masculino - a música caipira e a viola - , a Orquestra Viola de Saia rompe mais uma barreira imposta pela cultura capitalista inerente aos grandes centros. " $\mathrm{O}$ feminino é, pois, uma dimensão de resistência ao paradigma hegemônico neoliberal” (OLIVEIRA, 2008, p. 10).

Essa resistência, segundo Covre, faz parte da cultura do feminino, que é símbolo de luta pela vida, e que tem a paciência e a persistência.

\footnotetext{
"Poder-se-ia dizer que esse tipo de mulher (...) pode ter uma forma idealizada em Sherazade, aquela que cura e salva pela palavra e que sabe que a verdade não se dá em linha reta, mas por inúmeros labirintos". (MANZINI-COVRE, 1996, p. 19).
}

As lideranças femininas normalmente trabalham pela construção de uma cidadania centrada no sentir, a chamada cidadania ativa, que é justamente o ponto de partida para o conhecimento do corpo como um instrumento do fazer social.

\section{Metodologia}

A metodologia utilizada para a execução deste trabalho divide-se em três partes: a primeira analisou os conceitos teóricos de feminino e de cultura como construção de sentidos, conforme bibliografia citada; a segunda utilizou entrevistas semiestruturadas para obter informações formalizadas e captar o discurso dos entrevistados; e a terceira constituiu-se em uma observação participante, técnica de investigação social em que o observador partilha das atividades do objeto de estudo.

\section{Entrevistas}

As nove componentes do grupo foram entrevistadas e falaram da identificação com a música, as modas caipiras e a viola, o que esperam da Orquestra e como é ser mulher e atuar em um movimento tipicamente masculino.

\section{Relação com a música e com o instrumento}

Para Veneranda, a viola tem um significado muito maior que a música. "Eu tive que dar muitas voltas pra chegar até a viola. Primeiro aprendi a tocar teclado e depois sanfona. A viola é raiz, ela mexe com a gente, vai arrancando de dentro, o sentimento, a saudade, a lembrança... Eu choro", diz Veneranda com os olhos cheios de lágrimas.

Izabele tem só 11 anos e muito cedo entrou na aula de violão. Mas acompa- 
nhar o pai nas aulas de viola decidiu mudar de instrumento. Seu gosto musical é bastante refinado e entre os seus ídolos estão Almir Sater, Renato Teixeira, Sérgio Reis, Tião Carreiro, Sérgio Penna e Fabíola Mirella.

Fabíola recorda-se que já aos quatro anos de idade sentia uma forte ligação com viola, mesmo sem saber a diferença entre o instrumento e um violão. "Eu tinha um violãozinho de brinquedo que era meu amigo inseparável. Eu pegava uma cadeira e sentava na frente da TV, com ele e minhas chupetas, para assistir o programa da Inezita Barroso", lembra ela.

Nancy é musicista profissional, além de dar aulas de música, toca em eventos. Nascida em São Paulo, tem uma forte ligação com a música caipira. "Sempre gostei de música raiz e hoje realizo o meu sonho de entrar em contato com esse estilo musical", diz ela.

\section{Perspectivas com a Orquestra}

Maria Clara é a integrante mais nova, tanto de idade - 10 anos - quanto de tempo na Orquestra. Ela ainda está um pouco tímida, fala bem pouco, mas diz estar bastante feliz por fazer parte do grupo.

Irani formou uma dupla caipira com a irmã aos 21 anos e chegou a gravar um $\mathrm{CD}$, mas considera que foram passadas para trás, por falta de experiência. Ela espera um dia viver de música e não deixou o sonho de lado. "Quero trabalhar com música e espero que a orquestra me traga isso", diz ela.

Proprietária de uma empresa de informática, Maria Cristina não tem certeza se um dia pretende viver da música. "A minha empresa tem oito anos já, foi um caminho árduo pra chegar até aqui, eu amo o que eu faço, tecnologia."

\section{Uma orquestra só de mulheres}

Além de fazer parte da Orquestra Viola de Saia, Celina canta e toca na banda do marido, Carlos, que é violonista e violeiro. É a única mulher do grupo. Para ela, uma orquestra feminina imprime um diferencial. "Sabemos que na música a presença feminina não é muito velha. E na viola então? Muito preconceito fez com que as mulheres não mostrassem ou não desenvolvessem seus talentos. Uma orquestra feminina de viola acaba incentivando e fortalecendo a presença feminina na música em geral, e na viola em especial", diz ela.

Veneranda nem dá ouvidos para os que dizem que viola é coisa de homem e retruca. "Na verdade, eu acho a viola mais feminina do que masculina, porque é deli- 
cada, é um instrumento muito sentimental, a gente começa a tocar e viaja”, explica.

Para Alessandra, fazer parte de uma orquestra só de mulheres faz toda a diferença. "É nisso que eu aposto e acredito. É uma semente que está sendo plantada, mas quando for descoberta vai ser o grande diferencial."

\section{Observação participante}

Durante a observação participante, esta pesquisadora frequentou três ensaios da Orquestra Viola de Saia, nos dias 14 de março, 4 de abril e 9 de maio. O grande espaço de tempo entre os ensaios deu-se pelo número de feriados e emendas nos três meses.

Os ensaios começam normalmente às $16 \mathrm{~h}$ e encerram-se às $18 \mathrm{~h} 30$. Cerca de cinco músicas são tocadas, quantas vezes for necessário, para que todas tenham a oportunidade de treinar letra e melodia. $\mathrm{O}$ repertório é escolhido por Fabíola, pelo grau de dificuldade das músicas. Por enquanto, a orquestra só toca nos ensaios músicas com poucos acordes.

No primeiro dia de observação (14/3), só Veneranda não estava presente. Em um primeiro momento expliquei às integrantes da orquestra qual era a finalidade do trabalho e que, além de participar dos ensaios, precisaria entrevistá-las. Fui muito bem recebida e todas demonstraram satisfação pelo meu interesse no assunto.

Nesse mesmo dia Alessandra iniciou sua participação no grupo e levou seu pandeiro, que tem afinação específica para chorinho. Ela também tocou outros instrumentos, como um apito e caixa.

A primeira música tocada foi Cuitelinho, de Paulo Vanzolini e Antônio Xandó, cantada pela dupla Pena Branca e Xavantinho. A letra fala de saudade e algumas palavras são cantadas da mesma forma que faladas no interior do país. Ex: navaia = navalha, atrapaia $=$ atrapalha, zóio $=$ olhos, afrito $=$ aflito. Três tentativas.

Em seguida elas tocaram Samba de Roda, folclore recolhido por Geraldo Meireles, música com bastante percussão e em determinado momento acompanhada de palmas. Duas tentativas.

A terceira música é Folia de Reis, composta por Fabíola e Sérgio, e parece uma prece, fala da crença católica e da fé dos violeiros. Fabíola sugere que elas ensaiem somente a introdução, que parece ser o mais difícil. Três tentativas.

Fabíola fala com as companheiras sobre o CD. Ela diz que é preciso ensaiar bastante para gastar o menor número de horas de estúdio possível e pede para que 
todas ensaiem em casa também.

A música seguinte é Viola de Estimação, composta por Fabíola, que tem um diferencial, meio tom acima no final. A regente desafia as colegas a conseguirem o feito. Sem conseguir na primeira tentativa elas ensaiam a introdução e deixam as notas como lição de casa. Duas tentativas.

Fabíola está perdendo a voz e decide encerrar o ensaio. Colcha de Retalhos, de Raul Torres, cantada pela dupla Chitãozinho e Xororó, deveria ser a última música. A letra fala das diferenças sociais de um casal. A pedidos, Maria Cristina canta.

Sérgio pede mais uma para encerrar. O grupo canta Pagode em Brasília, de Teddy Vieira e Lourival dos Santos, cantada por Tião Carreiro e Pardinho.

O ensaio terminou por volta das $17 \mathrm{~h} 30$ com um café fresquinho feito pelo Sérgio Penna.

No segundo ensaio (4/4) só Izabele não estava presente. Fabíola trouxe um pequeno equipamento, chamado metrônomo, utilizado para fazer a marcação rítmica dos instrumentos e muito utilizado em estúdios.

O novo item foi suficiente para "atrapalhar" o andamento do ensaio. As meninas não conseguiam acompanhar, todas ao mesmo tempo, o tal aparelho. A consequência disso foi a interrupção do ensaio por diversas vezes.

Também foi a estréia de Veneranda tocando viola na orquestra, até então ela acompanhava os ensaios tocando percussão. Mais uma vez é a música Cuitelinho que inicia o ensaio. Elas sentem dificuldade com o metrônomo. Três tentativas. A segunda música foi Samba de Roda. A primeira vez é bastante difícil, na segunda já parece mais fácil.

Fabíola quis que a Orquestra tocasse músicas conhecidas com o metrônomo e sugere Pagode em Brasília. Ela acha que as meninas estão tocando e cantando muito alto, por isso têm dificuldade com o novo equipamento. Ela pede que elas desçam o tom. Três tentativas.

O metrônomo virou piada e todas começaram a criticá-lo, dizendo que seria necessário um ensaio só para aprender a usá-lo.

A quarta música é Sina de Violeiro, composta por Fabíola, que fala do amor de um violeiro pelo seu instrumento "Meu coração chora se não tem você viola para 
espantar o mau agouro da cidade". Sem metrônomo foi muito mais fácil. Elas se dividiram em duplas para cantar as estrofes. Fiquei emocionada com a letra da música e com as duplas formadas.

Em seguida elas tocam Folia de Reis para encerrar. Nesse dia todas saem apressadas, pois têm um compromisso. Um encontro de violeiros na casa de um amigo.

No último ensaio (9/5) faltaram Nancy e Celina, que estavam gripadas. Antes de iniciar os trabalhos do grupo, tomamos um gostoso café da tarde, com bolo de fubá, chocolate, pão com salsicha e frios. Todos aproveitaram para contar histórias de um tempo passado em um lugar bem distante da cidade grande, onde é possível andar descalço, correr na grama, tomar banho de rio e ver assombração na sexta feira santa.

Em volta da mesa estávamos eu, Fabíola, Sérgio, Izabele, Nivaldo (pai de Izabele), Irani, Maria Cristina, Alessandra, Maria Clara e Veneranda. Todos tinham uma história para contar. Foi um encontro com as raízes.

Naquele dia não teve metrônomo, para alívio de todas. Cuitelinho iniciou os ensaios. Maria Clara foi convidada a fazer parte da Orquestra e pela primeira vez tocou percussão com a mãe. Três tentativas.

A próxima música foi Colcha de Retalhos, cantada por Maria Cristina. Uma tentativa. Em seguida elas cantam a Moda da Mula Preta, de Raul Torres, gravada por Tonico e Tinoco. A música fala de uma mula muito bonita e especial que deu muito gosto ao seu dono e morre picada de cobra. O final foi um pouco difícil e elas retomam só esse pedaço. Duas tentativas.

A quarta música é Pagode em Brasília, mas as meninas erram um pedaço e só Izabele continua. Sérgio chamou a atenção do grupo e disse que em um show isso não pode acontecer. Esfria de repente e o grupo parece desatento. Três tentativas.

A próxima música é Dona Felicidade, de Teddy Vieira e todas ficam felizes porque conseguem tocar todos os acordes corretamente. Uma tentativa.

O ensaio é encerrado com Menino da Porteira, de Teddy Vieira e Luizinho, cantada por Sérgio Reis. Uma das músicas caipiras mais famosas, fala de um garoto que espera um boiadeiro na porteira. Certo dia o garoto morre pisoteado num estouro de boiada. A letra da música deu origem a um filme, rodado pela primeira vez em 1977 e refilmado em 2009. 


\section{Considerações finais}

O fato de nascer ou viver em uma cidade como São Paulo, pode ter o poder de extinguir certos laços, por conta das relações instrumentais, da busca pelas oportunidades. Mas não foi o que aconteceu com as mulheres da Orquestra Feminina Vila de Saia. A construção de sentidos proporcionada pela formação da orquestra teve como elemento primordial a trajetória individual de cada componente do grupo.

Todas as integrantes da Orquestra Feminina Viola de Saia têm uma ligação direta ou indireta com a viola e a cultura caipira, sempre relacionada às suas raízes familiares. Por isso, é tão importante para elas manter essa tradição, inclusive como forma de congraçamento, o que permite a criação de uma identidade. Essas conclusões remetem à dimensão do feminino discutida por Covre, onde a mulher assume para sim a responsabilidade de fazer diferença, com paciência e persistência.

Fica muito claro que o trabalho feito pela Orquestra vai muito além da necessidade de fazer parte da indústria cultural. Pode-se dizer que existe uma franca disposição para isso, já que as integrantes do grupo não descartam a possibilidade de fama e dinheiro. Porém, vale destacar que no contexto em que foi criada e no qual vem sendo desenvolvida, o prestígio, mesmo que em um meio restrito, é muito valorizado por estas mulheres. Isso acontece através da música e de um instrumento que está fora dos meios hegemônicos de comunicação. Também foi possível verificar o conflito entre a tradição e a modernidade, quando Fabíola levou um metrônomo para os ensaios e as integrantes da orquestra ficaram totalmente perdidas.

É possível afirmar que, em pleno século XXI, a sociedade brasileira continua machista. Apesar do trabalho feminino ser reconhecido em diversas áreas tradicionalmente masculinas, continua tendo um menor valor aos olhos do gênero oposto. Mesmo que as mulheres assumam posições de liderança, as negociações são estritamente masculinas. Isso não é diferente no mundo da viola caipira

Apesar de existirem mulheres de renome que tocam o instrumento, como Inezita e Barroso e Helena Meirelles (1924-2005), a figura da Viola de Saia causa certa surpresa, inclusive a que gerou este trabalho. E essa surpresa é ainda maior quando se percebe a diversidade de suas componentes.

Neste caso, é possível concluir que a cultura subalterna, apesar de ser um forte elemento de resistência, nem sempre está ligada diretamente às classes sociais de seus membros. Talvez suas origens desencadeiem um sentimento de obrigação ou reparação, que conduzam à construção de identidades culturais que justamente proporcione a igualdade. No universo da Viola de Saia essa igualdade é reconhecida e respeitada, todas têm um mesmo papel, independentemente do conhecimento mu- 
sical de cada uma.

A Orquestra Feminina Viola de Saia representa valores que sempre permearão a vida humana. Por mais que o universo viva em constante mudança, que as culturas se moldem aos novos padrões, sempre haverá alguém ou algum grupo disposto a não seguir um padrão hegemônico, mesmo que isso signifique viver à margem.

O espaço de conflitos oferecido pela cultura faz parte deste universo. Nem todos estão em busca somente do horário nobre da TV, mas também da construção de subjetividades que permitam a possibilidade de construção de sentidos e de identidades.

\section{Bibliografia}

BRANDÃO, Carlos Rodrigues. "Capiras, Capiaus: Pau-a-pique 1984”. Exposição, Centro de Lazer Sesc, Fábrica Pompéia.

CASCUDO, Luís da Câmara. "Dicionário do Folclore Brasileiro". São Paulo: Global, 2002.

FERREIRA, Maria Nazareth (org.). "Cultura subalterna e neoliberalismo: a encruzilhada da América Latina". São Paulo: CELACC, 1997.

. "Globalização e identidade cultural na América Latina: a cultura subalterna no contexto do neoliberalismo". São Paulo: CELACC, 2008.

HALL, Stuart. "Identidade Cultural". São Paulo: Fundação Memorial da América Latina, 1997.

MANZINI-COVRE, Maria de Lourdes. "No caminho de Hermes e Sherazade - cultura, cidadania e subjetividade". Taubaté: Vogal Editora, 1996.

NEPOMUCENO, Rosa. “Música caipira: da roça ao rodeio”. São Paulo: Ed. 34, 1999.

OLIVEIRA, Dennis de. "Culturas de grupos subalternizados: espaço para construção de novas subjetividades políticas”. Artigo. São Paulo, 2008

SOUSA, Walter. "Moda inviolada: uma história da música caipira”. São Paulo: Quiron, 2005.

THOMPSON, John B. "Ideologia e cultura moderna: teoria social crítica na era dos meios de comunicação de massa". Petrópolis, RJ: Vozes, 2000. 